\section{Chemoenzymatic synthesis of the alarm pheromone $(+)$-verbenone from geranyl diphosphate $\dagger$}

\author{
Zulfa Yoosuf-Aly, Juan A. Faraldos, David J. Miller and Rudolf K. Allemann* \\ Received 23rd April 2012, Accepted 25th May 2012 \\ DOI: $10.1039 / \mathrm{c} 2 \mathrm{cc} 32883 \mathrm{f}$
}

The enzyme-guided asymmetric synthesis of (+)-verbenone from geranyl diphosphate in a simple two-step, one pot transformation highlights the potential of chemoenzymatic procedures for the generation of high-value terpenoids.

With more than 30000 known members, terpenoids constitute the largest and most structurally diverse family of natural products. ${ }^{1}$ Monoterpenes are often found in natural, renewable extracts such as turpentine and are a source of commercially valuable synthetic fragrances, flavours, drugs, agrochemicals and synthetic building blocks. Plant derived terpenoids have diverse biological functions in communication or defence. ${ }^{2}$ Bark beetle infestations pose a major threat to conifer populations worldwide ${ }^{3}$ with millions of acres of pine trees having been lost due to attacks by mountain pine beetles such as Dendroctonus ponderosae. ${ }^{4}$ These beetles produce monoterpenoid pheromones for communication; the male beetle uses (+)- $\alpha$-pinene (2) produced by the tree for host selection and then converts it to verbenol, which acts as an attractant for female beetles. The beetles then produce the oxidation product $(+)$-verbenone (3), which acts as a dispersal pheromone to modulate the density of the attack. ${ }^{5,6}$ In a programme to limit tree damage from beetle infestation, foresters hang small bags of synthetic verbenone on trees as a beetle repellant. ${ }^{4}$ Verbenone is also a useful chiral synthon and has been used in the total synthesis of taxol. ${ }^{7}$ Furthermore this bioactive enone has been reported as an inhibitor of acetylcholine esterase and hence has potential for the treatment of early stage Alzheimer's disease. ${ }^{8}$

Recent work has revealed that several terpene cyclases accept analogues of prenyl diphosphates as substrates thereby opening up the possibility for the simple production of large numbers of modified terpenoids with potentially altered biological activity. ${ }^{9-18}$ For such syntheses to be viable, downstream modifications of the terpene synthase-generated acyclic or (poly)-cyclic hydrocarbon product(s) should preferably be performed in the same reaction vessel as the enzymatic step;

School of Chemistry and Cardiff Catalysis Institute,

Cardiff University, Main Building, Park Place, Cardiff, CF10 3AT,

United Kingdom.E-mail: allemannrk@cardiff.ac.uk;

Fax: + 44 (0)29208 74030; Tel: + 44 (0)29 20879014

$\dagger$ Electronic supplementary information (ESI) available: Details of PCR, enyzme expression and purification, synthetic methods, kinetic data and all analytical data of reaction products. See DOI: 10.1039/ c2 $\operatorname{cc} 32883 \mathrm{f}$

the hydrocarbons (in particular monoterpenes) are normally highly volatile (i.e. semiochemicals). Here we describe the asymmetric synthesis of $(+)$-verbenone from geranyl diphosphate $(\mathbf{1}$, GDP) that combines the enzymatic cyclisation of $\mathbf{1}$ with the chemical oxidation of the resulting $(+)-\alpha$-pinene (2) to produce $(+)$-verbenone (3) in good overall synthetic yield and without the need to isolate reaction intermediates (Fig. 1).

The chemical synthesis of $\alpha$-pinene (2) requires the synthesis of a [3.1.1]-bicyclo ring system, the control of the stereochemistry of two chiral centres and the regiospecific introduction of a trisubstituted double bond. The $\mathrm{Mg}^{2+}$-dependent monoterpene cyclase $\alpha$-pinene synthase (APS) achieves these complex synthetic tasks in one step from GDP (1) ${ }^{5,18}$ A codon optimised synthetic gene for APS from Pinus taeda was inserted into the vector pET21d for production of the enzyme in E. coli. To facilitate purification, a hexa-histidine tag $\left(\mathrm{His}_{6}\right)$ and a TEV cleavage site were inserted at the 3' end of the APS coding region. E. coli BL21 (DE3) RIL cells were transformed with the resulting plasmid, APS-His ${ }_{6}$ production induced with IPTG and the resulting APS recombinant protein purified by $\mathrm{Ni}^{2+}$-affinity chromatography (see ESI for details $\uparrow$ ).

The kinetics of the APS-His 6 catalysed turnover of GDP (1) to $(+)-\alpha$-pinene were followed by incubation with radiolabelled GDP and detection of the pentane soluble radiolabelled hydrocarbon products as previously described $(\mathrm{ESI} \dagger){ }^{5}$ The values of $K_{\mathrm{M}}=40 \pm 8 \mu \mathrm{M}$ and $k_{\mathrm{cat}}=0.001 \pm 0.0004 \mathrm{~s}^{-1}$ were in good agreement with those previously reported; ${ }^{5}$ the C-terminal hexahistidine tag did not appear to affect the activity of the enzyme and all further experiments were performed with APS-His 6 .

The ability of APS-His ${ }_{6}$ to quantitatively produce $\alpha$-pinene was checked on an analytical scale. APS-His ${ }_{6}(25 \mu \mathrm{M})$ was incubated with GDP $(2.0 \mathrm{mM}, 25 \mu \mathrm{L})$ in incubation buffer $(100 \mathrm{mM}$ Bis-Tris propane, $\mathrm{pH} 7.5,50 \mathrm{mM} \mathrm{KCl}$ and $100 \mathrm{mM}$ $\mathrm{MgCl}_{2}$ ) in a final volume of $0.5 \mathrm{~mL}$. The reaction was overlaid with $0.5 \mathrm{~mL}$ pentane. After gentle shaking overnight at room

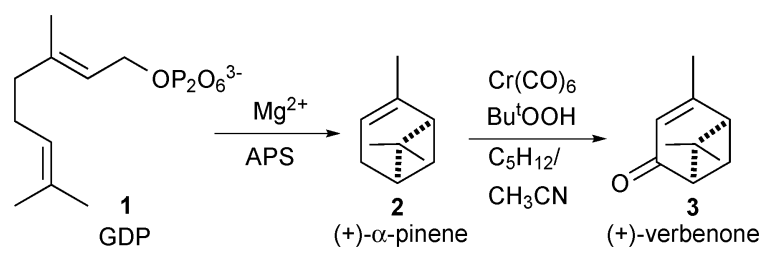

Fig. 1 Synthesis of (+)-verbenone (3) from enzymatically produced $(+)-\alpha$-pinene. 


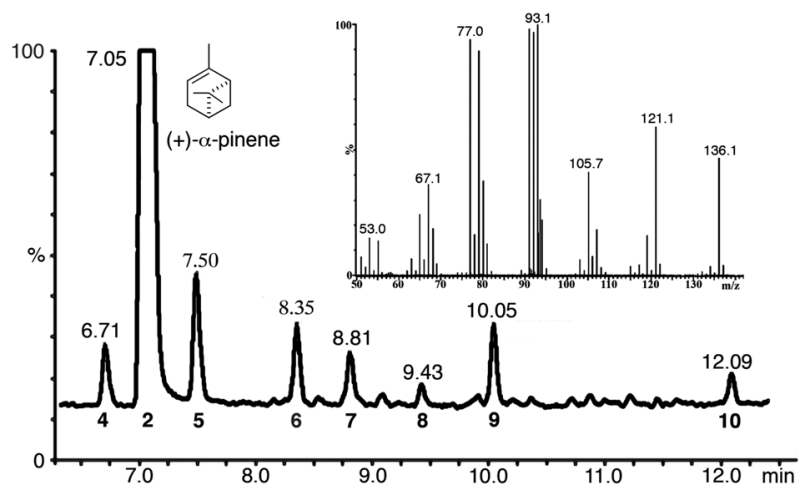

Fig. 2 Total ion chromatogram of the monoterpene products derived from GDP by APS-His 6 and $\mathrm{EI}^{+}$-mass spectrum of fraction eluting at $7.32 \mathrm{~min}$ (inset).

temperature, the organic layer was removed and the aqueous layer extracted with additional pentane $(0.5 \mathrm{~mL})$. The pooled pentane extracts were analyzed by GC-MS. The total ion chromatogram (TIC) showed a single major product ( $m / z$ 136) (Fig. 2), which was identified as $\alpha$-pinene by coelution with an authentic standard. As had been reported previously, ${ }^{5}$ the recombinant enzyme also generated small amounts of an unidentified monoterpene (4), camphene (5), $\beta$-pinene (6), $\beta$-myrcene (7), 3-carene (8), limonene (9) and terpinolene (10) in addition to $(+)-\alpha$-pinene (2), which constitutes $91 \%$ of the total amount of isolated products with $98 \%$ conversion from GDP (Fig. 2) (see ESI $\dagger$ ). All products except 4 were identified by co-elution with authentic material and from their mass spectra. From comparison of its mass spectrum with those available in the NIST (National Institute of Standards and Technology) library, $\mathbf{4}$ was tentatively identified as tricyclene (1,7,7-trimethyltricyclo-[2.2.1.0 2.6]-heptane, see ESI for MS and structure $\dagger)$. The enzyme derived $\alpha$-pinene was shown to be generated with $>98 \%$ enantiomeric excess by GC over a chiral stationary phase and comparison with authentic $( \pm)$ - $\alpha$-pinene (see ESI $\dagger$ ).

Several methods have been reported previously for the conversion of $\alpha$-pinene (2) to verbenone (3). Air oxidation of 2 is very unselective and produces several side products in addition to $3{ }^{19,20}$ Various homogeneous and heterogeneous catalysts have been reported for this conversion, ${ }^{21,22}$ including a three step process that uses $\mathrm{Pb}(\mathrm{OAc})_{4}$ followed by base-catalysed hydrolysis of the product and oxidation of the epimeric verbenol with $\mathrm{Na}_{2} \mathrm{Cr}_{2} \mathrm{O}_{7}{ }^{23}$ Conversion of $\mathbf{2}$ to $\mathbf{3}$ using cell suspension cultures from Psychotria brachyceras and Rauvolfia sellowii has also been reported. ${ }^{24}$ To convert GDP to 3 without the need to isolate the intermediate $\alpha$-pinene, a $\mathrm{Cr}(\mathrm{CO})_{6}$ catalysed oxidation of $\mathbf{2}$ with $t$-butyl hydroperoxide $\left({ }^{\mathrm{t}} \mathrm{BuOOH}\right)$ was developed. ${ }^{25}$ The simplicity and high yield of this methodology combined with the compatibility of the reagents with those of terpene synthasecatalysed reactions allowed the development of a two-phase system. A racemic sample of commercial $\alpha$-pinene was treated with $\mathrm{Cr}(\mathrm{CO})_{6}$ and ${ }^{\mathrm{t}} \mathrm{BuOOH}$ in acetonitrile or benzene and $( \pm)$-verbenone was isolated in $68 \%$ yield $(\mathrm{ESI} \dagger){ }^{25,26}$ Attempts to extract enzymatically produced $\alpha$-pinene with either benzene or $\mathrm{CH}_{3} \mathrm{CN}$ by overlaying incubations of GDS and APS-His 6 with these solvents failed due to the partial mixing with the aqueous solution that led to inactivation of the enzyme. Similarly, toluene and xylene also prevented the enzymatic reaction. However, the
$\mathrm{Cr}(\mathrm{CO})_{6}$ catalysed oxidation of racemic pinene was efficient in pentane (Table 1).

In initial attempts to carry out the oxidation of APS-His 6 produced $\alpha$-pinene to 3, a large excess of ${ }^{\mathrm{t}} \mathrm{BuOOH}$ (15-30 molar equivalents relative to $\alpha$-pinene) was required due to the presence of $\beta$-mercaptoethanol ( $\beta \mathrm{ME})$. Hence purified APS was dialysed to remove $\beta \mathrm{ME}$ prior to use. Alternatively, the pentane solution of enzyme-produced $\alpha$-pinene could be passed through a short column of silica gel to remove $\beta \mathrm{ME}$ prior to $\mathrm{Cr}(\mathrm{CO})_{6} /{ }^{\mathrm{t}} \mathrm{BuOOH}$ oxidation in a different reaction vessel.

The limited solubility of $\mathrm{Cr}(\mathrm{CO})_{6}$ in pentane made use of 20 molar equivalents of this reagent necessary. $\mathrm{CH}_{3} \mathrm{CN}$ is known to act both as a solvent and a ligand in $\mathrm{Cr}(\mathrm{CO})_{6}$ catalysed oxidation reactions, ${ }^{27}$ addition of a small amount of $\mathrm{CH}_{3} \mathrm{CN}\left(10 \% \mathrm{v} \mathrm{v}^{-1}\right)$ to the pentane led to the efficient oxidation of 2 by ${ }^{t} \mathrm{BuOOH}$ in the presence of only 2 molar equivalents of $\mathrm{Cr}(\mathrm{CO})_{6}$. Four molar equivalents of ${ }^{\mathrm{t}} \mathrm{BuOOH}$ relative to the chromium reagent were required, consistent with previous studies employing this reaction. ${ }^{25}$

Hence the overall optimised procedure for one-pot conversions of GDP to (+)-verbenone was as follows. A dialyzed solution of APS-His ${ }_{6}$ solution was added to $2 \mathrm{mM}$ GDP in incubation buffer (ESI $\dagger$ ) and the solution was overlaid with pentane. The vessel was sealed to prevent loss of the volatile $\alpha$-pinene and was gently shaken for 24 h. $(+)$ - $\alpha$-Pinene (2) was obtained in $89 \%$ yield from GDP (1) as judged by GC-MS comparisons with authentic standards of known concentration (vide supra, also see ESI $\dagger$ ). The aqueous layer was then removed and extracted with further pentane. To the pooled pentane extracts was added $\mathrm{CH}_{3} \mathrm{CN}$, ${ }^{\mathrm{t}} \mathrm{BuOOH}$ and $\mathrm{Cr}(\mathrm{CO})_{6}$ followed by heating under reflux for $18 \mathrm{~h}$. After purification by HPLC, (+)-verbenone was isolated in $50 \%$ overall yield from GDP with $>95 \%$ purity as judged by GC-MS and ${ }^{1} \mathrm{H}$-NMR spectroscopy (Fig. 3). The slightly lower yield relative to the reaction carried out in $\mathrm{CH}_{3} \mathrm{CN}$ could be attributed to use of pentane as a solvent which likely reduces the stability (and solubility) of the $\mathrm{Cr}(0)$ catalyst. Although less efficient than $\mathrm{CH}_{3} \mathrm{CN}$ in the single step reaction, pentane was essential for effective conversion of GDP to $3\left([\alpha]_{\mathrm{D}}^{20}=+233.3 \mathrm{dm}^{-1} \mathrm{~cm}^{3} \mathrm{~g}^{-1}\right.$, $c=0.06$ in $\mathrm{CHCl}_{3}$ ) in this study. (+)-Verbenone was produced in $>98 \%$ ee as judged by chiral GC comparison with both racemic and commercial (-)-verbenone (ESI $\dagger$ ). Using this methodology

Table 1 Optimisation of the solvent system and reagent requirements for the chemoenzymatic synthesis of verbenone (3) from GDP (1)

\begin{tabular}{lllll}
\hline $\begin{array}{l}{[\beta \mathrm{ME}] \text { in aq. }} \\
\text { buffer }(\mathrm{mM})\end{array}$ & $\mathrm{Cr}(\mathrm{CO})_{6}{ }^{a}$ & $\mathrm{Bu}^{\mathrm{t}} \mathrm{OOH}^{a}$ & Organic solvent & $\begin{array}{l}\text { Yield } \\
(\%)\end{array}$ \\
\hline 5 & $-{ }^{b}$ & $-{ }^{b}$ & $\mathrm{CH}_{3} \mathrm{CN}$ & $<1^{b}$ \\
5 & $-{ }^{b}$ & $-{ }^{b}$ & $\mathrm{C}_{6} \mathrm{H}_{6}$ & $<1^{b}$ \\
5 & $-^{b}$ & $-{ }^{b}$ & $\mathrm{C}_{6} \mathrm{H}_{5} \mathrm{CH}_{3}$ & $<1^{b}$ \\
5 & 10 & 15 & $p-\mathrm{xylene}^{b}$ & $<1$ \\
5 & 20 & 30 & $n-\mathrm{C}_{5} \mathrm{H}_{12}$ & $<3$ \\
5 & 20 & 30 & $n-\mathrm{C}_{5} \mathrm{H}_{12}$ & $<3$ \\
0 & 2 & 8 & $n-\mathrm{C}_{5} \mathrm{H}_{12}$ & $40^{c}$ \\
0 & 8 & $10 \% \mathrm{CH}_{3} \mathrm{CN}$ in $n-\mathrm{C}_{5} \mathrm{H}_{12}$ & $50^{c}$
\end{tabular}

${ }^{a}$ Molar equivalents relative to GDP. ${ }^{b}$ Yield is for $\alpha$-pinene only, insufficient quantities were isolated for the oxidative step to be carried out. ${ }^{c}$ Overall isolated yield of $(+)$-verbenone (3). As with the oxidation of commercial racemic $\alpha$-pinene the remaining material was mostly unreacted $\alpha$-pinene, in addition to small amounts of unidentified by-products. $\beta \mathrm{ME}, 2$-mercaptoethanol. 


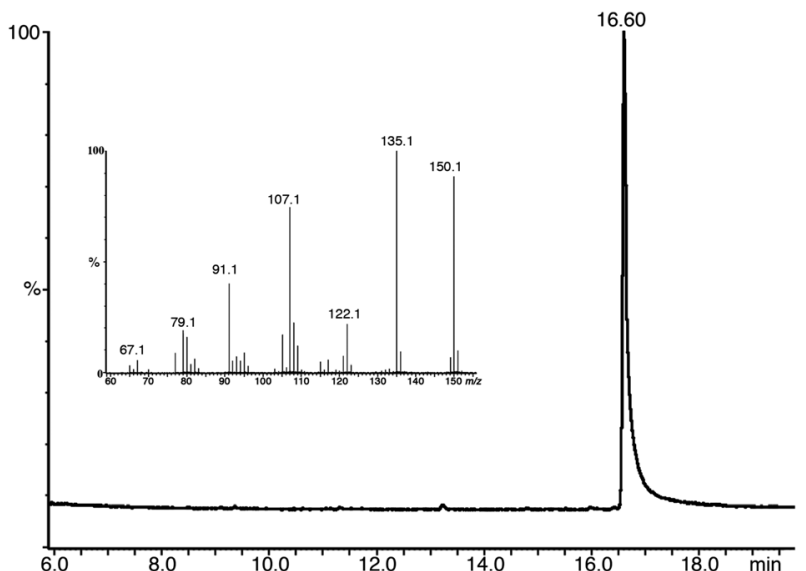

Fig. 3 Total ion chromatogram of chemoenzymatically synthesised (+)-verbenone (3). Inset: $\mathrm{EI}^{+}$-mass spectrum of $\mathbf{3}$.

a production capacity of $150 \mathrm{mg} \mathrm{L}^{-1}$ of (+)-verbenone was achieved.

In summary, the asymmetric two-step synthesis of $(+)$-verbenone from GDP highlights the potential of chemoenzymatic procedures to produce high-value terpenoids. While $\alpha$-pinene (2) is a relatively cheap starting material, the known promiscuity of many terpene synthases should allow the methodology described here to be used equally well for the production of analogues of verbenone (3) with high stereochemical precision starting from chemically modified GDPs. These engineered verbenone analogues may display enhanced biological activities due to the potential improvement of their physical properties such as stability or volatility essential for the fight of serious insect infestations. The methodology should also be potentially applicable to the large scale production of more complex terpenes such as gossypol, artemisinin or taxol, and indeed modified versions of these compounds from synthetically modified farnesyl- or geranylgeranyl-diphosphates, where the hydrocarbon precursors $\delta$-cadinene, amorphadiene and taxadiene are not readily available commercially, thereby opening up the possibility to produce large libraries of bioactive compounds with relative ease. With no limit on the amounts of both the starting materials and the biocatalysts, this methodology could be used for large-scale production of such compounds.

This work was supported by the United Kingdom's Biotechnology and Biological Sciences Research Council through grants $\mathrm{BB} / \mathrm{G} 003572 / 1$ and $\mathrm{BB} / \mathrm{H} 01683 \mathrm{X} / 1$, by the Engineering and Physical Sciences Research Council through grant EP/D069580/1 and by Cardiff University. We would like to thank Dr Rob Jenkins, Cardiff University, for assistance with HPLC purification and mass spectrometry.

\section{References}

1 J. Degenhardt, T. G. Kollner and J. Gershenzon, Phytochemistry, 2009, 70, 1621-1637.

2 D. J. McGarvey and R. Croteau, Plant Cell, 1995, 7, 1015-1026.

3 M. A. Johnson and R. Croteau, ACS Symp. Ser., 1987, 325, 76-92.

4 R. Petkewich, Chem. Eng. News, 2008, 86, 36-37.

5 M. A. Phillips, M. R. Wildung, D. C. Williams, D. C. Hyatt and R. Croteau, Arch. Biochem. Biophys., 2003, 411, 267-276.

6 G. J. Blomquist, R. Figueroa-Teran, M. Aw, M. M. Song, A. Gorzalski, N. L. Abbott, E. Chang and C. Tittiger, Insect Biochem. Mol. Biol., 2010, 40, 699-712.

7 P. A. Wender and T. P. Mucciaro, J. Am. Chem. Soc., 1992, 114, 5878-5879.

8 D. Kaufmann, A. K. Dogra and M. Wink, J. Pharm. Pharmacol., 2001, 63, 1368-1371.

9 D. J. Miller, F. L. Yu, D. W. Knight and R. K. Allemann, Org. Biomol. Chem., 2009, 7, 962-975.

10 D. J. Miller, F. L. Yu and R. K. Allemann, ChemBioChem, 2007, 8, $1819-1825$.

11 J. A. Faraldos, D. J. Miller, V. Gonzalez, Z. Yoosuf-Aly, O. Cascón, Li. Amang and R. K. Allemann, J. Am. Chem. Soc., 2012, 134, 5900-5908.

12 J. A. Faraldos, Y. X. Zhao, P. E. O'Maille, J. P. Noel and R. M. Coates, ChemBioChem, 2007, 8, 1826-1833.

13 D. J. Miller and R. K. Allemann, Nat. Prod. Rep., 2012, 29, 60-71.

14 F. Karp, Y. Zhao, B. Santhamma, B. Assink, R. M. Coates and R. B. Croteau, Arch. Biochem. Biophys., 2007, 468, 140-146.

15 F. Lopez-Gallego, S. A. Agger, D. Abate-Pella, M. D. Distefano and C. Schmidt-Dannert, ChemBioChem, 2010, 11, 1093-1106.

16 L. S. Vedula, Y. X. Zhao, R. M. Coates, T. Koyama, D. E. Cane and D. W. Christianson, Arch. Biochem. Biophys., 2007, 466, 260-266.

17 D. E. Cane, G. H. Yang, Q. Xue and J. H. Shim, Biochemistry, 1995, 34, 2471-2479.

18 D. W. Christianson, Chem. Rev., 2006, 106, 3412-3442.

19 Y. W. Suh, N. K. Kim, W. S. Ahn and H. K. Rhee, J. Mol. Catal. A: Chem., 2003, 198, 309-316.

20 M. K. Lajunen, T. Maunula and A. M. P. Koskinen, Tetrahedron, 2000, 56, 8167-8171.

21 A. L. Canepa, E. R. Herrero, M. E. Crivello, G. A. Eimer and S. G. Casuscelli, J. Mol. Catal. A: Chem., 2011, 347, 1-7.

22 M. Selvaraj, M. Kandaswamy, D. W. Park and C. S. Ha, Catal. Today, 2010, 158, 286-295.

23 M. R. Sivik, K. J. Stanton and L. A. Paquette, Org. Synth., 1995, 72, 57-61.

24 R. P. Limberger, A. M. Aleixo, A. G. Fett-Neto and A. T. Henriques, Electron. J. Biotechno., 2007, 10, 500-507.

25 A. J. Pearson, Y. S. Chen, G. R. Han, S. Y. Hsu and T. Ray, J. Chem. Soc., Perkin Trans. 1, 1985, 267-273.

26 R. B. Bates and V. P. Thalacker, J. Org. Chem., 1968, 33, $1730-1732$.

27 J. Muzart, Chem. Rev., 1992, 92, 113-140. 